\title{
Surgical Management of Portal Cavernoma Cholangiopathy
}

\author{
Vibha Varma*, Arunanshu Behera ${ }^{\dagger}$, Leileshwar Kaman ${ }^{\dagger}$, Somnath Chattopadhyay ${ }^{\star}$, Samiran Nundy* \\ *Department of Surgical Gastroenterology and Liver Transplantation, Sir Ganga Ram Hospital, New Delhi 110060, India and ${ }^{\dagger}$ Department of \\ Surgery, Postgraduate Institute of Medical Education and Research, Chandigarh 160012, India
}

\begin{abstract}
The majority of patients with portal cavernoma cholangiopathy (PCC) are asymptomatic, however some (5-38\%) present with obstructive jaundice, cholangitis, or even biliary pain due to bile duct stones which form as a result of stasis. Most patients with extrahepatic portal venous obstruction (EHPVO) present with variceal bleeding and hypersplenism and these are the usual indications for surgery. Those who present with PCC may also need decompression of their portosystemic system to reverse the biliary obstruction. It is important to realize that though endoscopic drainage has been proposed as a non-surgical approach to the management of PCC it is successful in only certain specific situations like those with bile duct calculi, cholangitis, etc. A small proportion of such patients will continue to have biliary obstruction and these patients are thought to have a mechanical ischemic stricture. These patients will require a second stage procedure in the form of a bilioenteric bypass to reverse the symptoms related to PCC. In the absence of a shuntable vein splenectomy and devascularization may resolve the PCC in a subset of patients by decreasing the portal pressure. (J Clin Exp Hepatol 2014;4:S77-S84)
\end{abstract}

$\mathrm{B}$ iliary abnormalities associated with portal hypertension, referred to as portal cavernoma cholangiopthy (PCC) have been reported since the 1980s. These changes were reported mainly in patients with extrahepatic portal venous obstruction (EHPVO) where the incidence was as high as $80-100 \%{ }^{1-6}$

The majority of patients with PCC are asymptomatic, however some present with obstructive jaundice, cholangitis, or even biliary pain due to bile duct stones which form as a result of stasis or repeated infections. Only $5-38 \%$ of patients with portal hypertension will have symptomatic PCC. ${ }^{4}$ Most patients with EHPVO present with variceal bleeding and hypersplenism and these are the usual indications for surgery. Those who present with PCC may also need decompression of their portal venous system to

Keywords: portal cavernoma cholangiopathy, extrahepatic portal venous obstruction, portal hypertension, portosystemic shunt surgery, biliary obstruction

Received: 3.4.2013; Accepted: 9.7.2013; Available online: 17.9.2013

Address for correspondence: Vibha Varma, Consultant, Department of Surgical Gastroenterology and Liver Transplantation, Sir Ganga Ram Hospital, New Delhi 110060, India.

E-mails: vibha.varma@gmail.com; vibha_verma2001@yahoo.com

Abbreviations: PCC: portal cavernoma cholangiopathy; EHPVO: extrahepatic portal venous obstruction; $\mathrm{PB}$ : portal biliopathy; $\mathrm{HJ}$ : hepaticojejunostomy; ERCP: endoscopic retrograde cholangiopancreatography; CBD: common bile duct; PSS: portosystemic shunt; NPSS: non-portosystemic shunt; IHBRD: intrahepatic biliary radical dilatation; EHBRD: extrahepatic biliary radical dilatation; PTBD: percutaneous transhepatic biliary drainage; LFT: liver function tests; NCPF: non cirrhotic portal fibrosis; UGI: upper gastrointestinal; GB: gall bladder http://dx.doi.org/10.1016/j.jceh.2013.07.005 reverse the biliary obstruction. In most patients the biliary changes are reversed by a portal decompressive procedures like a surgically created shunt because the distended varices in and around the bile duct then collapse. However there is a small group (28-50\%) of patients in whom PCC is not relieved after a shunt procedure and these will need drainage to reverse their biliary obstruction either via a stent or a surgical drainage procedure like a hepaticojejunostomy. ${ }^{7-11}$

These patients present late in life and have usually had repeated episodes of cholangitis and stent exchanges. 2-4\% of patients in whom the biliary obstruction has been present for a long time may go on to develop secondary biliary cirrhosis. ${ }^{12}$

\section{PRESENTING FEATURES}

Patients with EHPVO who develop symptomatic PCC (5$38 \%$ ), present with jaundice, pruritus and fever with chills and sometimes abdominal pain if there is associated stone disease. These patients present later, usually in the fourth decade, than those who are seen with variceal bleeding or hypersplenism where the mean age is younger. ${ }^{1-3,13}$ These patients may also have repeated episodes of cholangitis and a history of having had repeated endotherapy in the form of stenting, sphincterotomy, etc. A subgroup of patients who go on to develop secondary biliary cirrhosis present with ascites, a decreased serum albumin level and a deranged coagulation profile apart from a raised bilirubin. ${ }^{12}$

The primary indications for surgery in these patients with PCC may either be the biliary symptoms such as 
recurrent cholangitis which have necessitated repeated admissions for endoscopic therapy or for the usual indications for operation in patients with EHPVO i.e. recurrent gastrointestinal bleeding, hypersplenism, abdominal discomfort due to massive splenomegaly and growth retardation in children. Occasionally both sets of symptoms, PCC and bleeding etc. may coexist at presentation.

\section{DIAGNOSIS}

Apart from the altered biochemical parameters, a cholangiogram is mandatory to diagnose PCC. Previously, ERCP was used, but now with the availability of noninvasive tests like the MRCP, ERCP is only used when a bile duct decompression or stone extraction becomes necessary. ${ }^{12}$

The diagnostic modalities have two main goals-the first is to diagnose PCC and the second to identify which available vein will be most suitable to construct the portosystemic shunt procedure. This may be done using ultrasonography but now a CT angiography or an MR portovenography is used more frequently. These provide better visualization of the portal venous system as well as the systemic veins such as the renal vein and inferior vena cava which may be used in the anastomosis. ${ }^{14}$ Imaging also provides information about the architecture of the liver and the presence of ascites which indicates hepatic decompensation.

\section{MANAGEMENT OF PORTAL CAVERNOMA CHOLANGIOPATHY - OVERVIEW}

Once the decision has been taken to perform a portosystemic shunt its type is decided by the preference of the surgeon but, should be a non-selective shunt so that the whole portal venous system pressure is decompressed more effectively leading to regression of the pericholedochal collaterals. Portal decompression as a treatment for PCC was first described by Choudhuri et al in 1988 from India. ${ }^{15}$ Later several authors published their experience on the effectiveness of portosystemic shunts in PCC. Although the majority of these patients will benefit from portal decompression alone and not require biliary drainage there is a subset (30-50\%) who do not improve and require a biliary drainage procedure such as a Rouxen-Y hepaticojejunostomy. ${ }^{7,10}$ Direct biliary drainage has also been attempted but such procedures are often associated with torrential bleeding from the collaterals around the bile duct. It was then proposed that biliary drainage should be done at a later stage after the portal decompression as the pressure in the collaterals around the bile duct is reduced making the procedure less hazardous. ${ }^{9,16}$ It is also apparent that not all patients would require a second procedure and that portal decompression alone was effective in reversing the biliary obstruction in the majority of these patients. ${ }^{7,17}$ Those in whom the biliary obstruction was not reversed by a shunt procedure which was demonstrably patent, it was hypothesized that there was an element of ischemia which was responsible for the formation of irreversible mechanical strictures which would ultimately require a biliary drainage. ${ }^{2}$ Thus these patients who had a patent shunt and persistent jaundice, had either choledocholithiasis which had developed because of stasis, or had a dominant stricture. Those with bile duct stones can be treated with endotherapy and stenting if there was associated cholangitis. Those with strictures would require biliary drainage as a second stage procedure. ${ }^{17,18}$

With advances in endotherapy, patients with PCC are increasingly being managed with multiple stents for prolonged periods of time. One of the strong arguments in favor of operative management has been the fact that surgery is a onetime procedure, does not require repeated hospital visits, which is particularly relevant for the majority of EHPVO patients who come from areas where specialized medical help and access to endotherapy may not be available. $^{11}$

In many surgical series, there are a group of about 20 $47 \%$ of patients who are deemed as nonshuntable due to a lack of any suitable veins. This is because the entire portal venous system is obliterated and replaced by extensive collaterals. ${ }^{9,19,20}$ In such patients it might be worth performing an oesophagogastric devascularization procedure. Chattopadhyay et al reported that patients who underwent these nonshunt procedures also had a significant reduction in their serum bilirubin levels. ${ }^{11}$ Splenic artery ligation leads to reduction in the portal blood flow and portal pressure, which may lower the pressure in the pericholedochal collaterals leading to symptomatic improvement in PCC.

There are other surgeons who believe that no patient can have nonshuntable veins and they have performed a portosystemic anastomosis with any patent vein available like the inferior mesenteric vein, or even a large collateral vein to decompress the portal system with success. There have been few patients with PCC and nonshuntable veins, who have been offered liver transplantation. ${ }^{21-23}$ In them it is important to identify a portal inflow for the graft. However one needs to discuss the need for long term immunosuppression after transplant vis a vis other options available with these patients. A living related transplant has been done and justified in a patient who had both intrahepatic and extrahepatic biliary strictures which could not be corrected by a surgical biliary bypass. $^{21-23}$

There has also been a report of a case with EHPVO and PCC who did not have any shuntable vein and repeated attempts at biliary decompression led to life threatening bleeding from the pericholedochal collaterals. Percutaneous biliary drainage was performed for cholangitis, but 
an attempt at internalization into the duodenum via the common bile duct led to bleeding from periportal collaterals. Hence a novel approach was used by deploying a self-expanding metal stent between the stomach and the segment II bile duct. ${ }^{24}$

The literature is silent on the role of early portal decompression as a prophylactic procedure in EHPVO patients so that they do not develop symptomatic PCC. ${ }^{25}$ Authors believe that there is no role of prophylactic portosystemic shunt surgery in patients with asymptomatic PCC.

\section{SURGICAL OPTIONS}

Surgical options in a patient with PCC are aimed at decompression of the portal system to reduce the pressure in the collaterals which would take care of the biliary obstruction apart from treating the variceal hemorrhage, hypersplenism etc. This might be the only procedure required in the majority.

Decompression of the portal system is achieved by performing a non-selective portosystemic shunt. The type of shunt depends upon the preference of the surgeon, however the commonly performed shunts are proximal splenorenal shunt or a mesocaval shunt. A side-to-side splenorenal shunt is performed by some surgeons to preserve the spleen in young patients. Other makeshift shunts which are less frequently performed are meso-gonadal vein shunt, meso-renal shunt, or between a portal varix and cava. ${ }^{26-29}$ A Rex bypass (between the mesenteric vein and the left portal vein) is also performed in children with EHPVO. Portosystemic shunt and Rex bypass may be the only procedure required in majority of the patients with PCC. It might lead to regression of the pericholedochal collaterals and the PCC may not require any further treatment. ${ }^{30,31}$ However in a small subset of patients, a second stage procedure is required in the form of a biliary bypass (Roux-en-Y hepaticojejunostomy) to decompress the obstructed biliary system.

There would still remain a subset of patients who would not have a suitable shuntable vein. In this group it has been an observation by some that splenectomy devascularization alone will not only take care of the variceal bleed and hypersplenism but would also reduce the pressure in the pericholedochal collaterals (decreases the portal inflow as well as pressure) and might help in those having symptomatic PCC. ${ }^{11}$

The other rare surgical option for these patients having EHPVO and PCC is liver transplant. ${ }^{21-23}$ This option is applicable only for those patients who are troubled more by the PCC than hypersplenism or variceal bleed. If there is extensive porto-mesenteric thrombosis then the portal inflow to the graft is through the systemic circulation and that would in the form of either a cavoportal hemitransposition or a reno-portal inflow. This procedure unfortunately does not decompress the splanchnic bed and the patients would continue to have symptoms related to hypersplenism and esophagogastric varices.

\section{FOLLOW-UP}

Follow-up duration in various series has been between 14 months and 12 years. Resolution of PCC has been defined variously-symptomatic relief (itching, cholangitis and jaundice), biochemical resolution (reduction in bilirubin and alkaline phosphatise), and radiological improvement (resolution of biliary obstruction on cholangiogram). Doppler study and shunt patency may not correlate with outcome.

\section{THE RESULTS OF SURGERY}

Chaudhary et $\mathrm{al}^{7}$ in 1998 reviewed their experience in the management of patients with symptomatic PCC (Table 1). Out of 210 patients with EHPVO, 9 (4\%) were referred for the surgical management of PCC. Eight of these patients presented with jaundice, two of them with abdominal pain and one patient had repeated episodes of cholangitis. On ERCP, eight patients had a stricture of the bile duct and two had bile duct calculi (one with a stricture, one without a stricture). A direct attempt at biliary drainage in the early period resulted in excessive bleeding from which one patient died, another patient had repeated endotherapy and was advised a shunt procedure which he refused and was lost to follow-up.

Seven patients underwent a proximal splenorenal shunt, of whom three had complete resolution of their jaundice. However in four of them jaundice persisted despite their shunt being patent. Two of these had bile duct calculi which required endoscopic sphincterotomy and stone extraction, the other two underwent a staged procedure for biliary drainage (Roux-en-Y hepaticojejunostomy) 6 months following the shunt.

Khare et $\mathrm{al}^{8}$ reviewed their approach to the management of obstructive jaundice in patients with EHPVO (Table 1). They described 13 patients with PCC all of whom presented with obstructive jaundice. Seven patients had cholangitis, nine had variceal bleeding and three had hypersplenism. The median duration between the diagnosis of EHPVO and the development of jaundice was 8 years (range 1-11 years). The results of treatment were analyzed after grouping these patients into 3 categories. ${ }^{8}$ Group A $(n=5)$ had biliary strictures four of them underwent a splenorenal shunt and one of them had direct biliary drainage. In three of these patients the jaundice resolved. The remaining patient had a persistent stricture for which periodic endoscopic dilatation and stenting was required. Group B $(n=3)$ patients had bile duct calculi. One of them had staged procedures (a shunt followed by biliary drainage 5 months later). However this patient had a major bleed intraoperatively. One patient had a 
@ Table 1 Summary of Published Series on the Surgical Management of Portal Cavernoma Cholangiopathy.

\begin{tabular}{|c|c|c|c|c|c|}
\hline Authors & Numbers/age & Clinical presentation & Cholangiography & Surgical procedure & Outcome \\
\hline $\begin{array}{l}\text { Chaudhary et al } \\
1998,1987- \\
1995^{7}\end{array}$ & $\begin{array}{l}\text { EHPVO-PB } \\
9 / 210(4 \%) \\
\text { Mean age-21 years } \\
\text { Range: } 18-36 \text { years }\end{array}$ & $\begin{array}{l}\text { Jaundice-8 } \\
\text { Abdominal pain-2 } \\
\text { Recurrent cholangitis-1 }\end{array}$ & $\begin{array}{l}\text { ERCP } \\
\text { Stricture-8 } \\
\text { Bile duct calculi-2 }\end{array}$ & $\begin{array}{l}\text { Choledochojejunostomy-2 } \\
\text { Proximal splenorenal shunt- } \\
7\end{array}$ & $\begin{array}{l}\text { Anastomotic narrowing-1 } \\
\text { Died-1 } \\
\text { Recovered-3 } \\
\text { Persistent jaundice-4 } \\
\quad \text { Staged } \mathrm{HJ}-2 \\
\text { Endotherapy-2 }\end{array}$ \\
\hline $\begin{array}{l}\text { Khare R et al } \\
2005,1992- \\
2002^{8}\end{array}$ & $\begin{array}{l}\text { EHPVO-PB-13 } \\
\text { Medain age-21 years } \\
\text { Range: } 12-50 \text { years }\end{array}$ & Obstructive jaundice-13 & $\begin{array}{l}\text { A-Biliary stricture-5 } \\
\text { B-CBD stones-3 } \\
\text { C-Both-5 }\end{array}$ & $\begin{array}{l}\text { A-Splenorenal shunt-4 } \\
\text { B-Endotherapy-2 } \\
\text { Splenorenal shunt } \rightarrow \\
\text { HJ-1 } \\
\text { C-Failed endotherapy-4 } \\
\text { Splenorenal shunt } \rightarrow \\
\text { HJ-1 } \\
\text { Devascularisation-1 } \\
\text { Choledochoduodenos- } \\
\text { tomy-1 } \\
\text { Abandoned-2 }\end{array}$ & $\begin{array}{l}\text { Perioperative bleeding- } 4 \\
\text { Mortality-1 }\end{array}$ \\
\hline $\begin{array}{l}\text { Vibert et al } 2007 \text {, } \\
1980-2000^{9}\end{array}$ & $\begin{array}{l}\text { Symptomatic PB-19/ } \\
64(29 \%)\end{array}$ & $\begin{array}{l}\text { Cholestasis-19 } \\
\text { Cholangitis-7 }\end{array}$ & $\begin{array}{l}\text { PSS group-10 } \\
\text { IHBRD-9 } \\
\text { EHBRD-7 } \\
\text { Intrahepatic calculi-3 } \\
\text { NPSS group-9 } \\
\text { EHBRD-7 } \\
\text { Intrahepatic calculi-4 } \\
\text { Extrahepatic calculi-4 }\end{array}$ & $\begin{array}{l}\text { PSS group } \\
\text { PTBD \& stone } \\
\text { extraction-1 } \\
\text { Splenorenal shunt-10 } \\
\text { NPSS group } \\
\text { Endoscopic biliary } \\
\text { drainage-3 } \\
\text { Stone extraction-1 } \\
\text { Stenting-2 } \\
\text { PTBD-6 } \\
\text { Biliodigestive anasto- } \\
\text { mosis-4 }\end{array}$ & $\begin{array}{l}\text { PSS group, Mortality-nil } \\
\text { Early results } \\
\quad \text { Resolution of jaundice-7 } \\
\text { Long term } \\
\quad \text { Biliodigestive bypass-5 } \\
\text { NPSS group } \\
\text { Persistent jaundice \& repeated endother- } \\
\text { apy-2 } \\
\text { Combined endo \& percutaneous drainage- } 2 \\
\text { Repeated percutaneous cholangioscopies } \\
\text { \& stone removal-4 }\end{array}$ \\
\hline $\begin{array}{l}\text { Agarwal et al } \\
2010,1996- \\
2007^{10}\end{array}$ & $\begin{array}{l}\text { Symptomatic EHPVO-PB } \\
39 / 177(22 \%) \\
\text { Mean age-29.6 } \pm 12.5 \\
\text { years } \\
\text { Range: } 13-56 \text { years }\end{array}$ & $\begin{array}{l}\text { Jaundice-39 } \\
\text { Cholangitis-24 } \\
\text { Abdominal pain-24 } \\
\text { Variceal bleed-33 } \\
\text { Hypersplenism-7 }\end{array}$ & $\begin{array}{l}\text { Dominant stricture-15 } \\
\text { CBD calculi-7 } \\
\text { Gallstones-12 } \\
\text { IHBRD-39 }\end{array}$ & $\begin{array}{l}\text { Proximal splenorenal-37 } \\
\text { Hepaticojejunostomy- } 1^{\mathrm{b}} \\
\text { Devascularisation } \& \mathrm{HJ}-1^{\mathrm{C}} \\
\text { Second stage procedure- } \\
13^{\mathrm{d}} \\
\quad \mathrm{HJ}-11 \\
\text { Choledochojejuno- } \\
\text { stomy-1 } \\
\text { Cholecystectomy-1 }^{\mathrm{e}}\end{array}$ & $\begin{array}{l}\text { Abnormal LFTs-14 } \\
\text { Second stage- } 13^{\mathrm{d}} \text { Cholangitis-12 } \\
\text { Endotherapy-10 } \\
\text { Recurrent cholangitis-4 } \\
\text { CBD calculi-3 } \\
\text { Both-3 } \\
\text { Failed endotherapy-8 } \\
\text { Mortality-nil }\end{array}$ \\
\hline
\end{tabular}



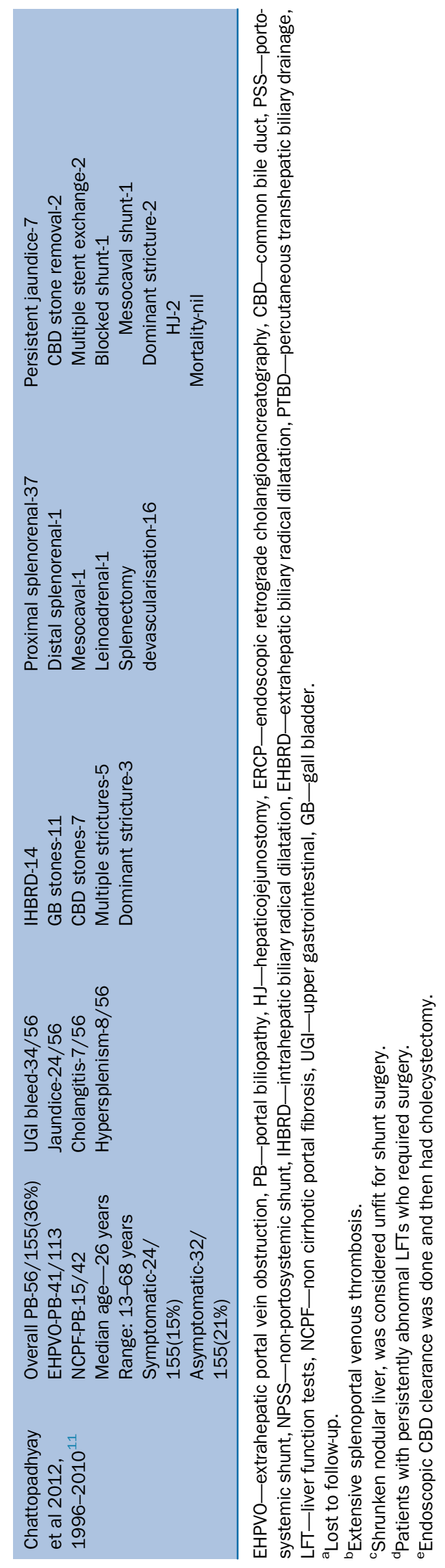

successful endoscopic stone extraction. The third patient, in whom endotherapy had failed initially, was found to have nonshuntable veins and hence a splenectomy and devascularization was performed. He continued to require multiple sittings of endotherapy. In Group C $(n=5)$ were patients who had biliary strictures and calculi. Endotherapy failed in four of them and surgery was attempted in all. The operation was abandoned in two because of massive intraoperative bleeding and splenectomy and devascularization was done in one patient for uncontrolled variceal bleeding. Two patients underwent endotherapy postoperatively, with the third being lost to follow-up. One patient had a staged procedure (shunt followed by biliary drainage after 4.5 months) and the remaining patient had a splenectomy and devascularization along with a choledochoduodenostomy. Thus only one patient had successful biliary drainage following a shunt procedure, with the others having massive bleeding during the attempts at biliary decompression.

Vibert et $\mathrm{al}^{9}$ in a retrospective review of 64 patients with portal cavernoma identified 19 (29\%) with symptomatic PCC (Table 1). All of them had jaundice and cholangitis was present in 7 patients. ${ }^{9}$ They followed a set protocol for managing these patients, which involved the initial treatment of cholangitis with antibiotics and percutaneous biliary drainage, followed by a portosystemic shunt to reduce the pressure in the collaterals which would not only relieve biliary obstruction in the majority, it would also facilitate the biliary drainage procedure. This was followed by a hepaticojejunostomy in those with persistent jaundice and who had a dominant stricture. Ten patients underwent splenorenal shunts and of the remaining 9 patients, 4 of them had nonshuntable veins due to widespread thrombosis, 3 had successful endoscopic biliary drainage before referral, and in 2 patients the diagnosis of PCC was not confirmed before surgery. Hence in the non-shunt group (9), biliary stenting (2), stone extraction (1), and percutaneous biliary drainage were performed for cholangitis (4), and pruritus (2). Four patients underwent biliodigestive anastomoses. In patients who underwent shunt procedures, 7 out of 10 were relieved of jaundice in the early follow-up period, however 5 of them required a biliary bypass later. Four of the 5 patients in the nonshunt group primarily managed with endoscopic drainage required repeated procedures for removal of intrahepatic calculi both via the endoscopic and percutaneous routes. The other 4 who underwent primary biliary drainage required percutaneous procedures for cholangitis and haemobilia later. The authors concluded that in patients with symptomatic PCC, it was preferable to perform a splenorenal shunt first which would take care of the jaundice in the majority of patients and in the remaining ones with persistent symptoms biliary drainage could be performed later more safely as a staged procedure. They recommended surgery over endotherapy. 
In another report, Agarwal et al prospectively reviewed their patients with EHPVO and PCC managed over a period of 11 years and emphasized the value of staged procedures $^{10}$ (Table 1). They had 39 patients with PCC (out of 177 with EHPVO i.e., 22\%) during this period who presented with jaundice (39), cholangitis (24), variceal bleeding (33), and hypersplenism (7). A dominant stricture was found on cholangiography in 15 patients, four of whom had multiple strictures. The surgical management plan was to perform a portosystemic shunt first in all patients. However two patients were excluded as one had extensive splenoportal thrombosis, and no shuntable vein and the other had a shrunken nodular liver discovered at surgery in whom a splenectomy and devascularization with biliary drainage was performed. Thirty seven patients underwent a proximal splenorenal shunt as the initial procedure. Fourteen patients had deranged liver function and they were found to have persistent dominant strictures (13) or angulation. They continued to have recurrent cholangitis (12), and abdominal pain (7). Thirteen patients underwent a second stage procedure (hepaticojejunostomy11, choledochojejunostomy-1, and cholecystectomy-1 following endoscopic clearance of their bile duct calculi if they were present). The authors recommend that in patients with EHPVO who have symptomatic PCC, a direct surgical approach at biliary drainage is hazardous and that a shunt decompresses the portal cavernoma and might resolve the biliary obstruction in the majority and in the others renders the second stage surgery safer because the portal hypertension has been largely reversed.

Chattopadhyay S et al reported 56 patients with PCC with non-cirrhotic portal hypertension, of whom there were 41 with EHPVO and 15 with $\operatorname{NCPF}^{11}$ (Table 1). They found that the mean age of EHPVO patients with PCC was significantly higher compared to those without PCC (26 years, range 13-50 years versus 18 years, range 4-57 years; $P=0.005)$. Jaundice was the presenting symptom in 24 (43\%) patients, cholangitis in 7/56 (12.5\%), variceal bleeding in $34(60.7 \%)$, and hypersplenism in $8(14 \%)$. Most of the patients had a portosystemic shunt (40/56); 16 patients had splenectomy and devascularization either because of an emergency presentation with massive bleeding or because of the lack of a suitable vein for a shunt procedure. Postoperatively, there was a significant decrease in the median bilirubin and serum alkaline phosphatase levels in those patients with symptomatic PCC $(1.8 \mathrm{mg} /$ $\mathrm{dl}$ to $1.0 \mathrm{mg} / \mathrm{dl} ; P<0.001$ and $150 \mathrm{IU} / \mathrm{mL}$ to $110 \mathrm{U} / \mathrm{mL}$, $P=0.003)$. Following splenectomy devascularization, they demonstrated that there was a significant decrease in the median bilirubin level $(1.9 \mathrm{mg} / \mathrm{dL}$ to $1.2 \mathrm{mg} / \mathrm{dL}$, $P=0.023)$, although the decrease in their serum alkaline phosphatase level was not significant $(105 \mathrm{IU} / \mathrm{mL}$ to $98 \mathrm{IU} / \mathrm{mL}, P=0.27$ ). On follow-up there were seven patients who had persistent jaundice; two of them had bile duct calculi which were successfully removed by endother- apy. One patient had a blocked splenorenal shunt and he underwent a mesocaval shunt for variceal rebleeding. The remaining four had patent shunts on follow-up; two of them were maintained on endotherapy and the other two underwent a second stage procedure in the form of a Roux-en-Y hepaticojejunostomy, as they required repeated stent exchanges for cholangitis. The authors suggested that wherever possible the primary surgical procedure for PCC should be a portosystemic shunt and in those patients who do not have a shuntable vein, splenectomy devascularization was also beneficial. This might be explained by the fact that splenectomy or splenic artery ligation is known to reduce the portal flow by $10-60 \%$, a concept sometimes used in the context of living donor liver transplantation to modify the portal flow in recipients suspected to have a high portal flow and a low graft-recipient weight ratio. $^{32,33}$ The proportion of patients who are amenable to shunt surgery in various published literature varies from 72 to $100 \% .^{7-11}$ Those deemed nonshuntable varies between 5 and $30 \%$. $^{7-11}$

Dhiman et al proposed an algorithmic approach to the management of patients with EHPVO and PCC. ${ }^{14}$ In patients who have no conventionally used shuntable veins one should look for any available vein in the region (e.g. inferior mesenteric vein, omental collateral etc) and use this to perform the portosystemic shunt. If despite these attempts if there is no vein available, one should consider performing a splenectomy devascularization procedure as this also has been found to reduce the flow in the portal vein and lower the pressure in the pericholedochal collaterals. This may, at best, lead to resolution of PCC and either avoid a second stage procedure (biliary drainage) or make it less difficult, if it is required for persisting symptoms.

Splenectomy and devascularization is not performed by choice, however this has been the surgical approach in those who do not have a shuntable vein. Published literature showing the outcome of this procedure in patients with PCC is sparse, there being only one report where the outcome was compared with those who had shunt surgery in terms of resolution of PCC. ${ }^{11}$ Hence this is not a recommendation but the authors have proposed it as a possibility to be considered in the absence of shuntable vein. The resolution of PCC is probably because of the reduced portal flow which occurs as a result of splenic artery ligation (experience extrapolated from liver transplant surgery) which might lead to reduced pressure in the pericholedochal collaterals and help in biliary decompression.

EHPVO constitutes a common cause for variceal bleed in the developing countries. As stated earlier, PCC is seen in $80-100 \%$ of patients with EHPVO; however it is symptomatic in only $5-38 \% .^{1-6}$ Though the numbers are small, there is no dearth of published data on the pathophysiology, diagnosis and management of PCC apart from the guidelines on the algorithmic approach 
to such patients. There are certain areas in the management which are still controversial and there is no clear cut way forward for example the role of prophylactic shunt in patients with asymptomatic PCC, the role of early shunts in symptomatic PCC as against primary role of endoscopic treatment, and the role of makeshift portosystemic shunt or splenectomy devascularization in patients with nonshuntable veins. However with the available data, management options especially the role of surgery has been outlined in the present review.

\section{CONCLUSION}

Endoscopic drainage has been proposed as a non-surgical approach to the management of PCC, however it is successful in only certain specific situations. It is now evident from the published literature that a portosystemic shunt as the primary treatment of patients with PCC is successful in the majority of cases. It is more likely to be successful in reversing the PCC if the shunt remains patent or in those who, do not have a dominant stricture, and have not had repeated episodes of cholangitis and stent exchanges. Patients who continue to remain symptomatic even after a shunt procedure will require endotherapy if there are bile duct calculi, or a second stage procedure in the form of a bilioenteric bypass for biliary strictures. Biliary drainage performed after a shunt procedure is fairly safe as the pericholedochal collaterals are decompressed following portosystemic shunt surgery. However it is only required in a subset of patients who have a persisting stricture, or who have had repeated stent exchanges or recurrent cholangitis. In the absence of any shuntable vein splenectomy and devascularization may resolve the PCC in a subset of patients by decreasing the portal pressure.

We believe it is time to review the current conservative management of PCC and replace it with early surgery in the form of portosystemic decompression procedures followed by a direct biliary enteric anastomoses, in patients in whom this does not reverse the biliary obstruction.

\section{CONFLICTS OF INTEREST}

All authors have none to declare.

\section{REFERENCES}

1. Dilawari JB, Chawla YK. Pseudosclerosing cholangitis in extrahepatic portal venous obstruction. Gut. 1992;33:272-276.

2. Khuroo MS, Yattoo GN, Zargar SA, et al. Biliary abnormalities associated with extrahepatic portal venous obstruction. Hepatology. 1993;17:807-813.

3. Nagi B, Kochhar R, Bhasin D, Singh K. Cholangiopathy in extrahepatic portal venous obstruction. Radiological appearances. Acta Radiol. 2000;41:612-615.

4. Sarin SK, Bhatia V, Makwane U. Portal biliopathy in extrahepatic portal vein obstruction. Indian J Gastroenterol. 1992;2:A82.
5. Chandra R, Kapoor D, Tharakan A, Chaudhary A, Sarin SK. Portal biliopathy. J Gastroenterol Hepatol. 2001;16:1086-1092.

6. Malkan GH, Bhatia SJ, Bashir K, et al. Cholangiopathy associated with portal hypertension: diagnostic evaluation and clinical implications. Gastrointest Endosc. 1999;49:344-348.

7. Chaudhary A, Dhar P, Sarin SK, et al. Bile duct obstruction due to portal biliopathy in extrahepatic portal hypertension: surgical management. Br J Surg. 1998;85:326-329.

8. Khare R, Sikora SS, Srikanth G, et al. Extrahepatic portal venous obstruction and obstructive jaundice: approach to management. J Gastroenterol Hepatol. 2005;20:56-61.

9. Vibert E, Azoulay D, Aloia T, et al. Therapeutic strategies in symptomatic portal biliopathy. Ann Surg. 2007;246:97-104.

10. Agarwal AK, Sharma D, Singh S, Agarwal S, Girish SP. Portal biliopathy: a study of surgically treated patients. HPB (Oxford). 2011;13:33-39.

11. Chattopadhyay S, Govindasamy M, Singla P, et al. Portal biliopathy in patients with non-cirrhotic portal hypertension: does the type of surgery affect outcome? HPB (Oxford). 2012;14:441-447.

12. Condat B, Vilgrain V, Asselah $T$, et al. Portal cavernoma-associated cholangiopathy: a clinical and MR cholangiography coupled with MR portography imaging study. Hepatology. 2003;37:1302-1308.

13. Sezgin O, Oguz D, Attintas E, Saritas U, Sahin B. Endoscopic management of biliary obstruction caused by cavernous transformation of the portal vein. Gastrointest Endosc. 2003;68:602-608.

14. Dhiman RK, Behera A, Chawla YK, Dilawari JB, Suri S. Portal hypertensive biliopathy. Gut. 2007;56:1001-1008.

15. Choudhuri G, Tandon RK, Nundy S, Misra NK. Common bile duct obstruction by portal cavernoma. Dig Dis Sci. 1988;33:1626-1628.

16. Bejanin H, Baumann R, Choury A, Fritsch J, Buffet C. Portal cavernoma compressing the bile duct. Apropos of three cases. Gastroenterol Clin Biol. 1993;17:134-138.

17. Dhiman RK, Puri P, Chawla Y, et al. Biliary changes in extrahepatic portal venous obstruction: compression by collaterals or ischemic? Gastrointest Endosc. 1999;50:646-652.

18. Chattopadhyay S, Nundy S. Portal biliopathy. World J Gastroenterol. 2012;18:6177-6182.

19. Poddar U, Thapa BR, Singh K. Endoscopic sclerotherapy in children: experience with 257 cases of extrahepatic portal venous obstruction. Gastrointest Endosc. 2003;57:683-686.

20. Dhiman RK, Chhetri D, Behera A, et al. Management of biliary obstruction in patients with portal hypertensive biliopathy (PHB) [abstract]. J Gastroenterol Hepatol. 2006;21:A505.

21. Filipponi F, Urbani L, Catalano G, et al. Portal biliopathy treated by liver transplantation. Transplantation. 2004;77:326-327.

22. Hajdu CH, Murakami T, Diflo T, et al. Intrahepatic portal cavernoma as an indication for liver transplantation. Liver Transpl. 2007;13: 1312-1316.

23. Gupta S, Singhal A, Goyal N, Vij V, Wadhawan M. Portal biliopathy treated with living donor liver transplant: index case. Exp Clin Transplant. 2011;9:145-149.

24. Mistry JH, Varma V, Mehta N, Kumaran V, Nundy S, Gupta A. Percutaneous transhepatic hepaticogastrostomy for portal biliopathy: a novel approach. Trop Gastroenterol. 2012;33:140-143.

25. Rao KLN, Thapa BR. Portal hypertensive biliopathy: can we prevent it? J Indian Assoc Pediatr Surg. 2010;15:1.

26. Kim HB, Pomposelli JJ, Lillehei CW, et al. Mesogonadal shunts for extrahepatic portal vein thrombosis and variceal hemorrhage. Liver Transpl. 2005;11(11):1389-1394.

27. Drews JA, Castagna J. Inferior mesorenal shunt as a second procedure for portal decompression. Surg Gynecol Obstet. 1976;142(1): 84-86.

28. Warren WD, Salam A, Smith RB. The meso-spleno-renal shunt procedures: a comprehensive approach to portasystemic decompression. Ann Surg. 1974;179(5):791-798. 
29. Camerlo A, Fara R, Barbier L, Grégoire E, Le Treut YP. Which treatment to choose for portal biliopathy with extensive portal thrombosis? Dig Surg. 2010;27:380-383. http://dx.doi.org/10. 1159/000314610.

30. Luoto T, Pakarinen M, Mattila I, Rintala R. Mesoportal bypass using a constructed saphenous vein graft for extrahepatic portal vein obstruction-technique, feasibility, and outcomes. J Pediatr Surg. 2012;4:688-693. http://dx.doi.org/10.1016/j.jpedsurg.2011. 10.065 .
31. Poddar U, Borkar V. Management of extra hepatic portal venous obstruction (EHPVO): current strategies. Trop Gastroenterol. 2011;32:94-102.

32. Lo CM, Liu CL, Fan ST. Portal hyperperfusion injury as the cause of primary nonfunction in a small-for-size liver graft-successful treatment with splenic artery ligation. Liver Transpl. 2003;9:626-628.

33. Sato Y, Yamamoto S, Oya H, et al. Splenectomy for reduction of excessive portal hypertension after adult living-related donor liver transplantation. Hepatogastroenterology. 2002;49:1652-1655. 